\title{
PRESERVAÇÃO DA QUALIDADE PÓS-COLHEITA DE KIWI 'BRUNO' PELO CONTROLE DO ETILENO'
}

\author{
MARCELO JOSÉ VIEIRA², LUIZ CARLOS ARGENTA³, \\ CASSANDRO VIDAL TALAMINI DO AMARANTE ${ }^{4}$, CRISTIANO ANDRÉ STEFFENS ${ }^{5}$, \\ AMANDA MARIA FURTADO DREHMER VIEIRA ${ }^{6}$
}

RESUMO - Objetivou-se determinar os efeitos do 1-MCP sobre a conservação pós-colheita de kiwi, cultivar Bruno, armazenado sob atmosfera do ar (AA) e atmosfera controlada (AC). Os frutos foram colhidos em abril de 2003 e 2004. Três dias após a colheita, parte dos frutos foi tratada com 1,0 $\mu$ L.L $\mathrm{L}^{-1}$ de 1-MCP e armazenada sob atmosfera do ar (AA) e AC com baixo etileno. O tratamento com 1-MCP retardou o aumento da taxa de produção de etileno e reduziu a respiração após remoção de câmara fria, resultando assim no retardo da perda de firmeza da polpa e na redução do desenvolvimento de pericarpo translúcido e senescente. O tratamento com 1-MCP não apresentou efeito significativo sobre os teores de sólidos solúveis. Frutos armazenados sob AA apresentaram alto metabolismo, resultando em baixo potencial de armazenamento, mesmo na presença do 1-MCP. Máxima conservação da qualidade pós-colheita de kiwi 'Bruno' foi observada em frutos tratados com 1-MCP e armazenados sob AC com baixo etileno.

Termos para indexação: Actinidia deliciosa, 1-MCP, atmosfera controlada, fisiologia pós-colheita, distúrbio fisiológico, firmeza de polpa.

\section{POSTHARVEST QUALITY PRESERVATION OF 'BRUNO’ KIWIFRUIT BY ETHYLENE CONTROL}

\begin{abstract}
This research was carried out to study the effects of 1-MCP on postharvest quality preservation of kiwi 'Bruno' storage under controlled atmosphere and air. Fruits were harvested in April 2003 and 2004. Three days after harvesting, part of the fruits was treated with $1.0 \mu \mathrm{L} . \mathrm{L}^{-1}$ of 1-MCP, while the other part remained untreated (control), and then both lots were stored under air (AA) and controlled atmosphere (CA) with low ethylene. The treatment with 1-MCP delayed the increase in ethylene production rate and reduced respiration of the fruit after removal from cold storage. This was associated with a delay of loss in flesh firmness and a reduction of pericarp translucent and senescent. Treatment with 1-MCP showed no significant effect on SS content. Fruit stored under AA showed high metabolism, resulting in a low storage potential, even when treated with 1-MCP. The greatest benefits on postharvest quality preservation of kiwifruit 'Bruno' was achieved in fruit treated with 1-MCP and stored in CA with low ethylene.

Index terms: Actinidia deliciosa, 1-MCP, controlled atmosphere, postharvest physiology, physiological disorder, flesh firmness.
\end{abstract}

\footnotetext{
${ }^{1}$ (Trabalho 078-09). Recebido em: 03-04-2009. Aceito para publicação em: 18-01-2010.

${ }^{2}$ Eng. M.Sc. Centro de Ciências Agroveterinárias (CAV), Universidade do Estado de Santa Catarina (UDESC), Cx. Postal 281, CEP 88502-970, Lages-SC. E-mail: marcelo@renar.agr.br

${ }^{3}$ Eng. Agr. D.Sc. Estação Experimental de Caçador (Epagri), C. P. 591, CEP 89500-000, Caçador-SC. E-mail: argenta@epagri.rct-sc.br ${ }^{4}$ Eng. Agr. Ph.D. Centro de Ciências Agroveterinárias (CAV), Universidade do Estado de Santa Catarina (UDESC), Cx. Postal 281, CEP 88502-970, Lages-SC. E-mail: amarante@cav.udesc.br

${ }^{5}$ Eng. Agr. Dr. Centro de Ciências Agroveterinárias (CAV), Universidade do Estado de Santa Catarina (UDESC), Cx. Postal 281, CEP 88502-970, Lages-SC. E-mail: a2cs@cav.udesc.br

${ }^{6}$ Eng. Agr. M.Sc. Centro de Ciências Agroveterinárias (CAV), Universidade do Estado de Santa Catarina (UDESC), Cx. Postal 281, CEP 88502-970, Lages-SC. E-mail: a8amf@cav.udesc.br
} 


\section{INTRODUÇÃO}

A produção brasileira de kiwi concentra-se na região Sul, com destaque para cultivar Bruno, que apresenta baixo requerimento de horas de frio hibernal (SCHUCK, 2008), sendo a colheita realizada normalmente nos meses de abril e maio. A adoção de técnicas para aumento da conservação da qualidade dos frutos é essencial para a expansão do período de oferta e comercialização após a colheita. A maioria das práticas de manejo pós-colheita usadas atualmente para prolongar a vida pós-colheita de kiwi envolve a redução dos efeitos do fito-hormônio etileno e da respiração climatérica.

A sensibilidade de frutos à ação do etileno varia com a espécie, concentração do fito-hormônio e o tempo de exposição. O kiwi tem sido considerado uma das espécies cujos frutos apresentam a maior sensibilidade ao etileno (CRISOSTO et al., 2000). Pesquisas sugerem que a presença de etileno em concentrações inferiores a $10 \mathrm{~nL} . \mathrm{L}^{-1}$ de etileno no ambiente de armazenamento é suficiente para rápido amolecimento dos frutos. As principais consequências do etileno no ambiente de armazenamento estão relacionadas à perda de firmeza de polpa e à rápida senescência dos frutos (ARPAIA et al., 1994), reduzindo assim o período de conservação.

Considerando que o etileno tem papel crítico sobre o amadurecimento e a conservação pós-colheita de kiwi, várias estratégias têm sido adotadas visando a inibir a síntese e/ou ação desse hormônio. A refrigeração dos frutos após a colheita reduz a taxa respiratória e retarda a deterioração da qualidade de kiwi (MITCHELL, 1994). Mesmo assim, o potencial de armazenamento de kiwi em ambiente refrigerado sob atmosfera do ar é limitado a três meses, dependendo da cultivar (BONGUI, 1996). O armazenamento sob atmosfera controlada (AC) envolve o monitoramento e o controle das concentrações de oxigênio $\left(\mathrm{O}_{2}\right)$, gás carbônico $\left(\mathrm{CO}_{2}\right)$ e em alguns casos do etileno, além da temperatura e umidade relativa, constituindo-se em uma alternativa para aumento do potencial de conservação da qualidade dos frutos após a colheita em relação à AA (MAZARO et al., 2000). O uso de $\mathrm{AC}$ com $2,0 \mathrm{kPa}$ de $\mathrm{O}_{2}$ e $5,0 \mathrm{kPa} \mathrm{CO} \mathrm{CO}_{2}$ pode estender o período de conservação de kiwi em mais de seis meses (ARPAIA et al., 1986). Contudo, para que as técnicas de refrigeração e $\mathrm{AC}$ sejam eficientes, deve-se evitar expor os frutos ao etileno, mesmo que a exposição ocorra por poucos minutos (ARPAIA, 1994). A remoção do etileno, em ambiente de armazenamento de kiwi, é recomendada para conservação por longos períodos (CRISOSTO et al., 2000), podendo ser obtida com a utilização de agentes oxidantes do etileno, como o permanganato de potássio $\left(\mathrm{KMnO}_{4}\right)$.

O 1-metilciclopropeno (1-MCP) interfere na habilidade dos frutos em responderem ao etileno por se ligar de forma irreversível ao seu sítio receptor (BLANKENSHIP; DOLE, 2003). Atualmente, o 1-MCP é amplamente usado comercialmente em câmaras de armazenamento de maçã e pera, especialmente para melhorar a conservação da firmeza da polpa e retardar o desenvolvimento de distúrbios fisiológicos associados à ação do etileno.

Objetivou-se determinar o efeito do 1-MCP sobre a conservação pós-colheita de kiwi, cultivar Bruno, armazenado sob atmosfera do ar e atmosfera controlada.

\section{MATERIAL E MÉTODOS}

Dois experimentos foram conduzidos com kiwi (Actinidia deliciosa) cultivar Bruno. Os frutos foram colhidos em abril de 2003 e 2004, em pomar comercial localizado no município de FraiburgoSC. Após a colheita, foram selecionados frutos de tamanho uniforme e sem defeitos, os quais foram posteriormente homogeneizados e separados aleatoriamente em quatro grupos para a formação das amostras experimentais. No experimento I, frutos tratados com 1-MCP e sem tratamento foram armazenados sob atmosfera do ar (AA), enquanto no experimento II, frutos tratados com 1-MCP e sem tratamento foram armazenados sob atmosfera controlada (AC).

\section{Geração, aplicação e medidas da concentração de 1-MCP:}

Os frutos foram resfriados a $2^{\circ} \mathrm{C}$ logo após a colheita. Parte dos frutos de cada experimento foi tratada com 1,0 $\mu \mathrm{L} . \mathrm{L}^{-1}$ de 1-MCP três dias após a colheita em câmara hermética de $1 \mathrm{~m}^{3}$, durante $24 \mathrm{~h}$, enquanto outra parte dos frutos permaneceu sem receber o produto, sob as mesmas condições, correspondendo ao tratamento-controle. O gás 1-MCP foi gerado misturando-se EthylBlock ${ }^{\mathrm{TM}}(0,14 \%$ de 1-MCP, Rohm and Haas Química Ltda.) e água a $25^{\circ} \mathrm{C}$, num frasco de $500 \mathrm{~mL}$, conectado a câmara de tratamento. O gás 1-MCP foi bombeado para a câmara de tratamento num sistema fechado, durante $15 \mathrm{~min}$ (tempo necessário para atingir a concentração de interesse). A concentração de 1-MCP durante o tratamento foi determinada por cromatografia gasosa (ARGENTA et al., 2003), usando-se gás 1-MCP (AgroFresh Inc., PA, EUA) como padrão.

\section{Condições de armazenamento:}

Os frutos foram armazenados em câmaras comerciais carregadas com kiwi 'Bruno', em 
Fraiburgo-SC. No experimento I, os frutos foram armazenados sob AA $\left(0,0 \pm 0,5^{\circ} \mathrm{C}\right.$ e UR $\left.90 \pm 3 \%\right)$, e no experimento II sob AC $\left(2,0 \mathrm{kPa}\right.$ de $\mathrm{O}_{2}+4,5 \mathrm{kPa}$ de $\mathrm{CO}_{2} / 0^{\circ} \mathrm{C} \pm 0,5^{\circ} \mathrm{C}$ e UR $92 \pm 3 \%$ ) com baixo etileno. Os frutos foram submetidos à $\mathrm{AC}$ um dia após a aplicação do 1-MCP. Em ambas as condições de armazenamento (AA e AC), a temperatura do ambiente de armazenamento foi monitorada em intervalo de seis horas, com auxílio de um termômetro de mercúrio, enquanto a umidade relativa foi analisada semanalmente, com o auxílio de psicrômetro. As concentrações de $\mathrm{O}_{2}$ e $\mathrm{CO}_{2}$ foram monitoradas a cada hora por analisadores eletroquímicos e IRGA, respectivamente, e ajustadas automaticamente pela injeção de ar atmosférico e/ou adsorção do $\mathrm{CO}_{2}$ por carvão ativado. Um sistema de oxidação do etileno do ar foi usado para prevenir o acúmulo de etileno no ambiente sob AC. As concentrações de etileno foram periodicamente determinadas em ambos os ambientes de armazenamento (AA e AC).

\section{Análise dos frutos:}

As avaliações da qualidade dos frutos foram realizadas na colheita e, periodicamente, durante o armazenamento. Para o experimento I, as avaliações foram realizadas após 30; 60; 90 e 120 dias de armazenamento refrigerado, mais um e sete dias a $23^{\circ} \mathrm{C}$. No caso do experimento II, as avaliações foram realizadas após 60; 90; 120 e 150 dias de armazenamento refrigerado, mais um e sete dias a $23^{\circ} \mathrm{C}$. Durante o período de prateleira (sete dias a $23^{\circ} \mathrm{C}$ ), os frutos ficaram expostos ao etileno $\left(1,0 \mu \mathrm{L} \cdot \mathrm{L}^{-1}\right)$.

Os frutos dos dois experimentos foram analisados quanto à firmeza da polpa, teor de sólidos solúveis (SS), acidez titulável (AT), taxas respiratória e de produção de etileno, e incidência de distúrbios fisiológicos.

A análise da firmeza da polpa foi realizada em um lado da superfície de cada fruto, onde previamente foi removida a epiderme, pela utilização de um penetrômetro com ponteira de $8 \mathrm{~mm}$ de diâmetro (Guss, África do Sul). Para as análises de SS e AT, foi extraído o suco de amostra de tecido da secção equatorial dos frutos. O teor de SS foi determinado com auxílio de um refratômetro digital com compensação automática da temperatura (Atago, Tókio). A AT foi determinada com auxílio de um titulador automático (Radiometer, Lyon, França), por meio da titulação de $4 \mathrm{ml}$ de suco, diluídos em $20 \mathrm{ml}$ de água, até $\mathrm{pH} 8,1$ com hidróxido de sódio $0,1 \mathrm{~N}$. Para análise de incidência de pericarpo translúcido e pericarpo senescente, foram realizados cortes na secção transversal de cada fruto, atribuindo-se notas (1 - ausência; 2 - presença). As avaliações da taxa de produção de etileno e taxa respiratória foram realizadas diariamente, após o armazenamento, em 2003. Amostras de frutos foram colocadas em jarras de $4 \mathrm{~L}$, supridas com ar comprimido, livre de etileno, com fluxo de $100 \mathrm{~mL} \cdot \mathrm{min}^{-1}$, e mantidas a $23^{\circ} \mathrm{C}$. As concentrações de etileno e $\mathrm{CO}_{2}$ no ar efluente foram determinadas por cromatografia gasosa, conforme descrito por Argenta et al. (2003).

\section{estatística: \\ Delineamento experimental e análise \\ Os experimentos foram conduzidos em deli-} neamento inteiramente casualizado. Para as análises de firmeza da polpa e distúrbios fisiológicos, foram utilizados, em cada ano, 20 repetições (cada repetição correspondendo a um fruto). Para determinação de AT e SS, foram utilizadas, em cada ano, quatro repetições de cinco frutos. Devido à ausência de efeito interativo entre os anos de estudo (2003 e 2004) os dados foram analisados em conjunto. Para determinação da taxa de produção de etileno e taxa respiratória foram utilizadas três repetições, constituídas de seis a sete frutos.

Os dados foram submetidos à análise da variância, e a diferença mínima significativa entre tratamentos e períodos de armazenamento, determinada pelo teste de Fisher $(\mathrm{p}<0,05)$, utilizando o programa SAS.

\section{RESULTADOS E DISCUSSÃO}

Os frutos apresentaram, na colheita, firmeza da polpa de aproximadamente $67 \mathrm{~N}$ e teor de SS de $8,3 \%$, em 2003, e firmeza da polpa de $63 \mathrm{~N}$ e teor de SS de 8,7\%, em 2004.

$\mathrm{O}$ tratamento com 1-MCP frequentemente retardou o aumento acentuado da taxa de produção de etileno (Figura 1) e reduziu as taxas respiratórias (Figura 2) durante o período de prateleira, após remoção de câmara fria, dependendo da atmosfera e do período de armazenamento. Esses resultados evidenciam o efeito do tratamento 1-MCP sobre o controle do amadurecimento de kiwi.

O aumento da produção de etileno após o armazenamento sob AC foi menor em frutos tratados com 1-MCP em relação a frutoscontrole, especialmente depois de 90 e 120 dias de armazenamento (Figura 1). A máxima taxa de produção de etileno em frutos-controle mantidos sob AC foi observada aos cinco e seis dias a $23^{\circ} \mathrm{C}$, após 90 e 120 dias de armazenamento a $0^{\circ} \mathrm{C}$, respectivamente.

Frutos-controle armazenados sob AA apresentaram baixa taxa de produção de etileno durante os sete dias a $23^{\circ} \mathrm{C}$, mesmo após 60 dias de armazenamento refrigerado (Figura 1). Já, 
frutos tratados com 1-MCP e armazenados sob AA apresentaram aumento da taxa de produção de etileno durante os sete dias a $23^{\circ} \mathrm{C}$, após 90 e 120 dias de armazenamento a $0^{\circ} \mathrm{C}$. A baixa capacidade de produção de etileno de frutos-controle após 90 e 120 dias de armazenamento sob AA pode ser atribuído ao estádio avançado de amadurecimento dos frutos, indicado pelos baixos valores de firmeza da polpa (Figura 3), alto índice de frutos com pericarpo translúcido (Tabela 1) e, especialmente, pelo desenvolvimento de pericarpo senescente (Tabela 2). Segundo Brecht e Kader (1984), o desenvolvimento de senescência pode danificar o sistema enzimático responsável pela conversão do ACC em etileno. A redução da capacidade de produção de etileno após o armazenamento sob baixa temperatura também pode estar associada ao desenvolvimento de injúria pelo frio ou da sua interação com o desenvolvimento de senescência. No estudo, não foi identificado injúria pelo frio.

Frutos-controle armazenados sob AA exibiram taxa respiratória significativamente superior àquela de frutos tratados com 1-MCP, independentemente do período de armazenamento (Figura 2). A baixa taxa de produção de etileno em frutos-controle armazenados sob AA (Figura 1), em associação ao desenvolvimento de senescência (Tabela 2), sugere que o aumento acentuado da taxa respiratória destes frutos, após 90 e 120 dias de armazenamento a $0^{\circ} \mathrm{C}$, ocorreu, em parte, devido à ativação do metabolismo fermentativo. Análises informais indicaram aroma alcoólico nos frutoscontrole armazenados por 90 ou 120 dias sob AA, mais sete dias a $23^{\circ} \mathrm{C}$.

Os principais indicadores do fim do armazenamento de kiwi são o amolecimento da polpa a níveis críticos inferiores a $18 \mathrm{~N}$ e o desenvolvimento de podridões e/ou distúrbios fisiológicos; entretanto, para o consumo, os frutos devem apresentar firmeza da polpa entre 7 e $9 \mathrm{~N}$ (ARPAIA et al., 1994).

A redução da firmeza de polpa foi acentuada após 30 e 60 dias de armazenamento, em frutos sob $\mathrm{AA}$ e $\mathrm{AC}$, respectivamente, durante os sete dias a $23^{\circ} \mathrm{C}$ (Figura 3 ), em ambos os anos. Resultado semelhante de perda da firmeza da polpa foi observado por Manolopoulou e Papadopoulou (1997) nas cultivares Bruno, Monty e Hayward, após seis semanas de armazenamento sob $\mathrm{AC} \mathrm{a} 0^{\circ} \mathrm{C}$. A máxima conservação da firmeza ocorreu em frutos tratados com 1-MCP e armazenados sob AC (Figura 3).

As perdas de firmeza da polpa de kiwi 'Bruno', nos dois primeiros meses mais sete dias a $23^{\circ} \mathrm{C}$, foram de 66 e $46 \%$ para o tratamento-controle e 1-MCP, respectivamente, quando armazenado sob
AC, e 94 e $82 \%$ para o tratamento-controle e 1-MCP, respectivamente, quando armazenado sob AA. Esses resultados evidenciam o efeito aditivo do tratamento 1-MCP e da AC sobre o retardamento do amolecimento dos frutos. Houve rápida deterioração da firmeza da polpa durante armazenamento sob AA, mesmo quando os frutos foram tratados com 1-MCP. Isto foi relacionado, em parte, à presença de etileno em concentrações acima de $200 \mathrm{~nL} . \mathrm{L}^{-1}$, enquanto sob AC, a concentração de etileno no ambiente de armazenamento manteve-se inferior a $40 \mathrm{~nL} . \mathrm{L}^{-1}$ durante todo o período experimental. Resultados semelhantes foram observados por Brackmann et al. (1995), quando kiwis 'Monty', 'Abbot', 'Bruno' e 'Hayward', mantidos sob AA, amadureceram rapidamente após 72 dias de armazenamento na presença de etileno.

A partir de 60 dias de armazenamento sob AC ou AA, mais um e sete dias a $23^{\circ} \mathrm{C}$, houve pequena mudança na firmeza da polpa em frutos-controle e tratados com 1-MCP (Figura 3). No entanto, frutos tratados com 1-MCP mantiveram-se com firmeza da polpa significativamente superior àquela de frutoscontrole durante todo o período de armazenamento e de amadurecimento a $23^{\circ} \mathrm{C}$. Crisosto et al. (2000) também observaram perda do benefício do 1-MCP sobre a conservação da firmeza da polpa em kiwis 'Hayward' armazenados sob AA após quatro semanas. $\mathrm{O}$ fato de o 1-MCP efetivamente retardar a perda de firmeza, apenas nas primeiras semanas de armazenamento, sugere que a possível inibição da ação do etileno pelo 1-MCP em kiwi é superada pela síntese de novos receptores para o etileno. Após este período, as diferenças entre frutos tratados com 1-MCP e frutoscontrole refletem a manutenção de firmeza da polpa durante o período em que o produto esteve ativo.

Os principais eventos relacionados à perda da firmeza da polpa em kiwi são a degradação do amido em SS, a degradação de componentes da parede celular e o decréscimo no potencial osmótico (ARPAIA et al., 1987). A relação entre firmeza da polpa, potencial osmótico e turgor celular em kiwi ainda precisa ser elucidada (BONGUI et al., 1996). Segundo Arpaia et al. (1987), frutos armazenados sob AC mantêm o conteúdo de amido de 2 a 4 vezes superior em relação àqueles armazenados sob AA. Esses autores sugerem que a conversão do amido em SS é o principal evento relacionado ao rápido amolecimento de frutos nos estágios iniciais de redução da firmeza. Bongui et al. (1996) observaram que a atividade da enzima $\alpha$-amilase em kiwi é maior logo após a colheita, declinando simultaneamente com a redução da firmeza da polpa dos frutos, e que o aumento da atividade de enzimas envolvidas na degradação de componentes da parede celular só é considerado o principal evento 
no amolecimento dos frutos nos estágios avançado de amadurecimento.

Considerando a firmeza da polpa de $18 \mathrm{~N}$ como limite inferior para classificação, embalagem e comercialização dos frutos e $7 \mathrm{~N}$ correspondente ao limite de firmeza da polpa para consumo, o tratamento 1-MCP aumentou o potencial de armazenamento em aproximadamente 30 dias para frutos armazenados sob AA, e em 60 dias para frutos armazenados sob AC (Figura 3).

A firmeza da polpa e o teor de SS são os atributos de qualidade mais importantes para a determinação do ponto de colheita e qualidade durante o armazenamento, sendo que a AT tem importância apenas na qualidade pós-colheita (BRACKMANN et al., 1995). Kiwis apresentam um elevado conteúdo de ácidos. Os valores são próximos a $2 \%$ da massa fresca da polpa quando os frutos atingirem a maturação, declinando lentamente após a colheita (MITCHELL, 1994).

Observou-se redução da AT durante armazenamento e durante teste de prateleira para frutos de ambos os experimentos. A máxima conservação da AT foi observada em frutos armazenados sob AC, após 60 e 90 dias mais um ou sete dias a $23^{\circ} \mathrm{C}$ (Figura 3). Não houve efeito significativo do tratamento 1-MCP, quando associado ao armazenamento sob $\mathrm{AC}$, na conservação da $\mathrm{AT}$, assim como não houve efeito do 1-MCP sobre a redução da atividade respiratória (Figura 2). Em frutos armazenados sob AA, observou-se decréscimo linear da AT durante todo o período de armazenamento e prateleira, e benefício do tratamento 1-MCP sobre a manutenção da AT (Figura 3). Neves et al. (2003) observaram maior conteúdo de ácidos em kiwi 'Bruno' tratado com 1-MCP e armazenado sob AA.

O conteúdo de SS aumentou durante o armazenamento sob AA e AC (Figura 3). Somente nos frutos armazenados sob $\mathrm{AA}$, na análise realizada com 30 dias mais um dia a $23^{\circ} \mathrm{C}$, o tratamento com 1-MCP manteve menor o teor de SS. Neves et al. (2003) verificaram menor conteúdo de SS em kiwi 'Bruno' armazenado sob AA e tratado com 1-MCP, enquanto Waclawovsky et al. (2001) não observaram estes efeitos em kiwis 'Bruno' e 'Hayward'.

A aceleração do amolecimento de frutos durante o armazenamento, na presença de etileno pode levar ao desenvolvimento de distúrbios fisiológicos. O desenvolvimento e a severidade de frutos com pericarpo translúcido ou senescente aumentam com a duração do armazenamento (ARPAIA et al., 1994). O tratamento com 1-MCP em frutos armazenados sob AA e sob AC resultou em menor desenvolvimento de pericarpo translúcido durante todo o período de armazenamento, mais um e sete dias a $23^{\circ} \mathrm{C}$ (Tabela 1). O desenvolvimento desse distúrbio ocorreu após 90 e 120 dias de armazenamento sob AA, independentemente do tratamento com 1-MCP. A manifestação desse distúrbio sob AA ocorreu no primeiro mês de armazenamento em frutos-controle, após sete dias a $23^{\circ} \mathrm{C}$, sendo que após 60,90 e 120 dias de armazenamento, a totalidade dos frutos apresentaram desenvolvimento do distúrbio. $\mathrm{O}$ tratamento 1-MCP retardou o desenvolvimento do dano nos dois primeiros meses de armazenamento sob AA, com incidência significativamente inferior a frutos-controle após 90 e 120 dias de armazenamento (Tabela 1). Máximos benefícios do 1-MCP sobre a redução do desenvolvimento de pericarpo translúcido foram observados em frutos armazenados sob AC (Tabela 1).

O tratamento com 1-MCP preveniu o desenvolvimento de pericarpo senescente durante o armazenamento sob AA ou sob AC (Tabela 2). Sob AA, observou-se aumento crescente no desenvolvimento de senescência em frutos-controle, após 90 dias de armazenamento a $0^{\circ} \mathrm{C}$ mais sete dias a $23^{\circ} \mathrm{C}$. Entretanto, frutos tratados com $1-\mathrm{MCP}$ e armazenados sob AA ou sob AC não desenvolveram sintoma de senescência durante todo o período experimental. Contudo, frutos-controle armazenados em AC desenvolveram sintomas de senescência após 150 dias de armazenamento a $0^{\circ} \mathrm{C}$, mais sete dias a $23^{\circ} \mathrm{C}$ (Tabela 2 ). 


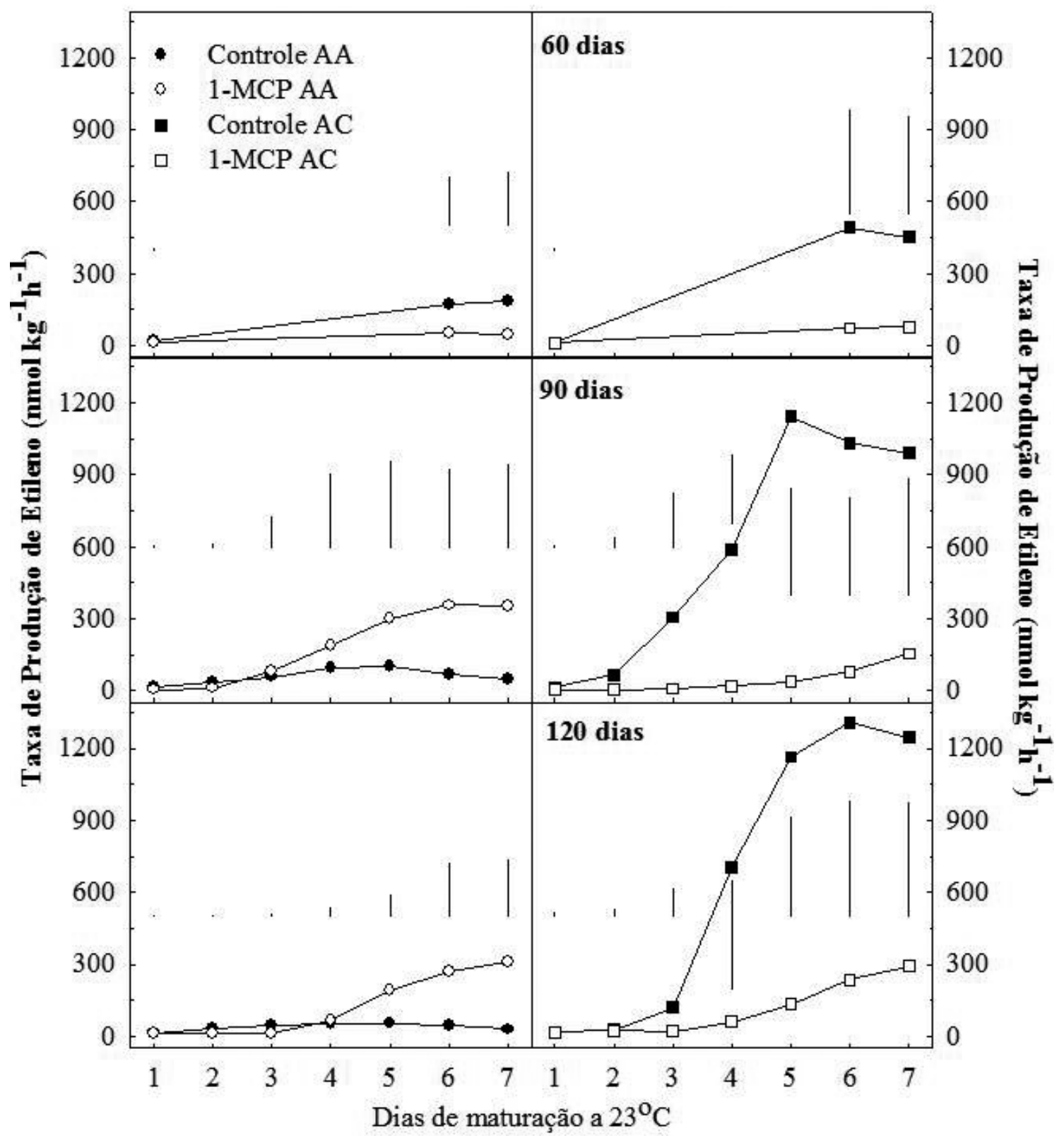

FIGURA 1 - Produção de etileno em kiwi 'Bruno' durante sete dias a 23ํㅡ, após 60; 90 e 120 dias de armazenamento sob atmosfera do ar (AA) e atmosfera controlada (AC com baixo etileno). As barras verticais no interior de cada gráfico representam as diferenças mínimas significativas entre tratamentos, calculadas pelo teste de Fischer $(\mathrm{p}<0,05)$. Fraiburgo-SC (2003). 


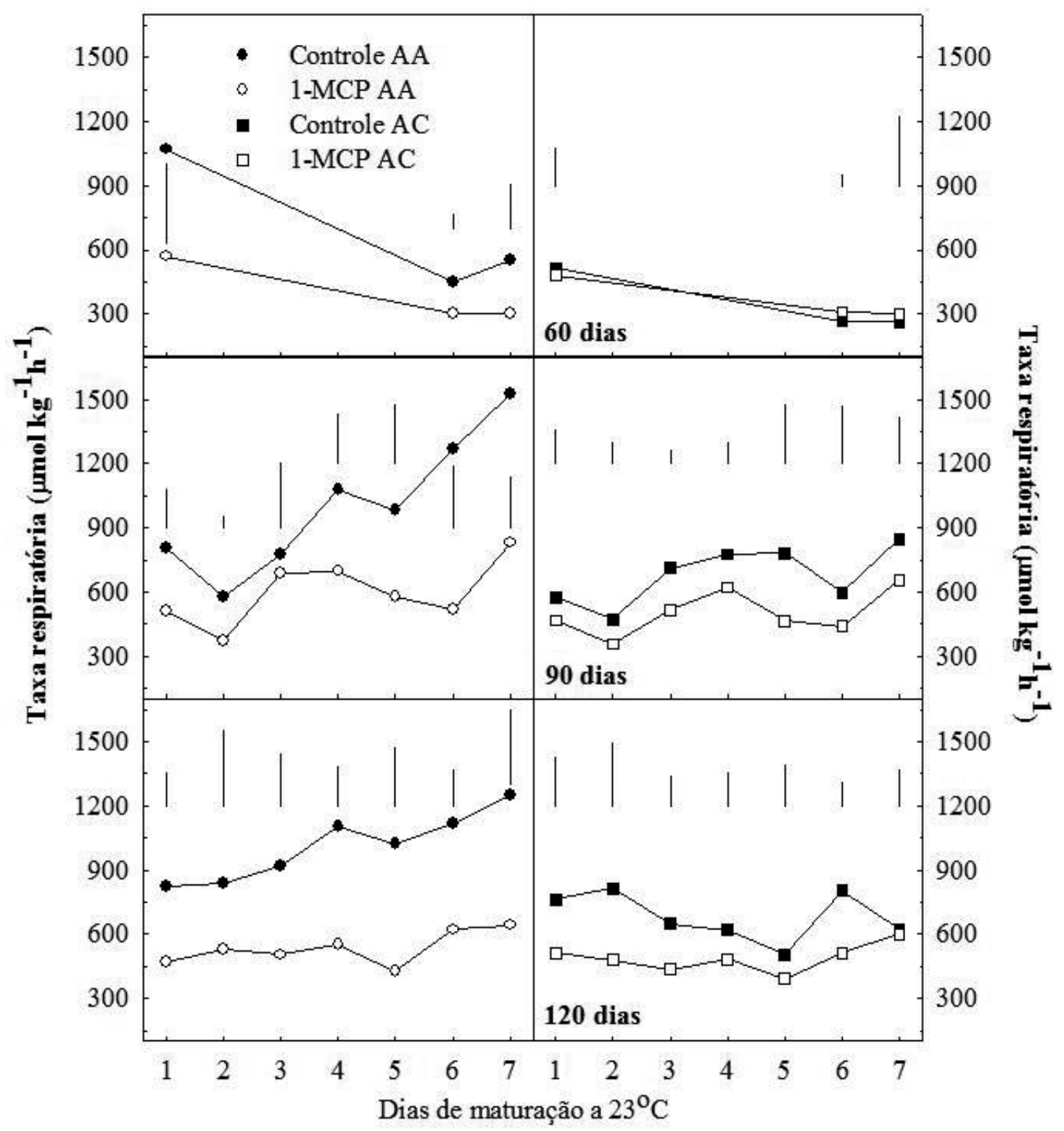

FIGURA 2 - Taxas respiratórias em kiwi ‘Bruno' durante sete dias a $23^{\circ} \mathrm{C}$, após $60 ; 90$ e 120 dias de armazenamento sob atmosfera do ar (AA) e atmosfera controlada (AC com baixo etileno). As barras verticais no interior de cada gráfico representam as diferenças mínimas significativas entre tratamentos, calculadas pelo teste de Fischer $(\mathrm{p}<0,05)$. Fraiburgo-SC (2003). 


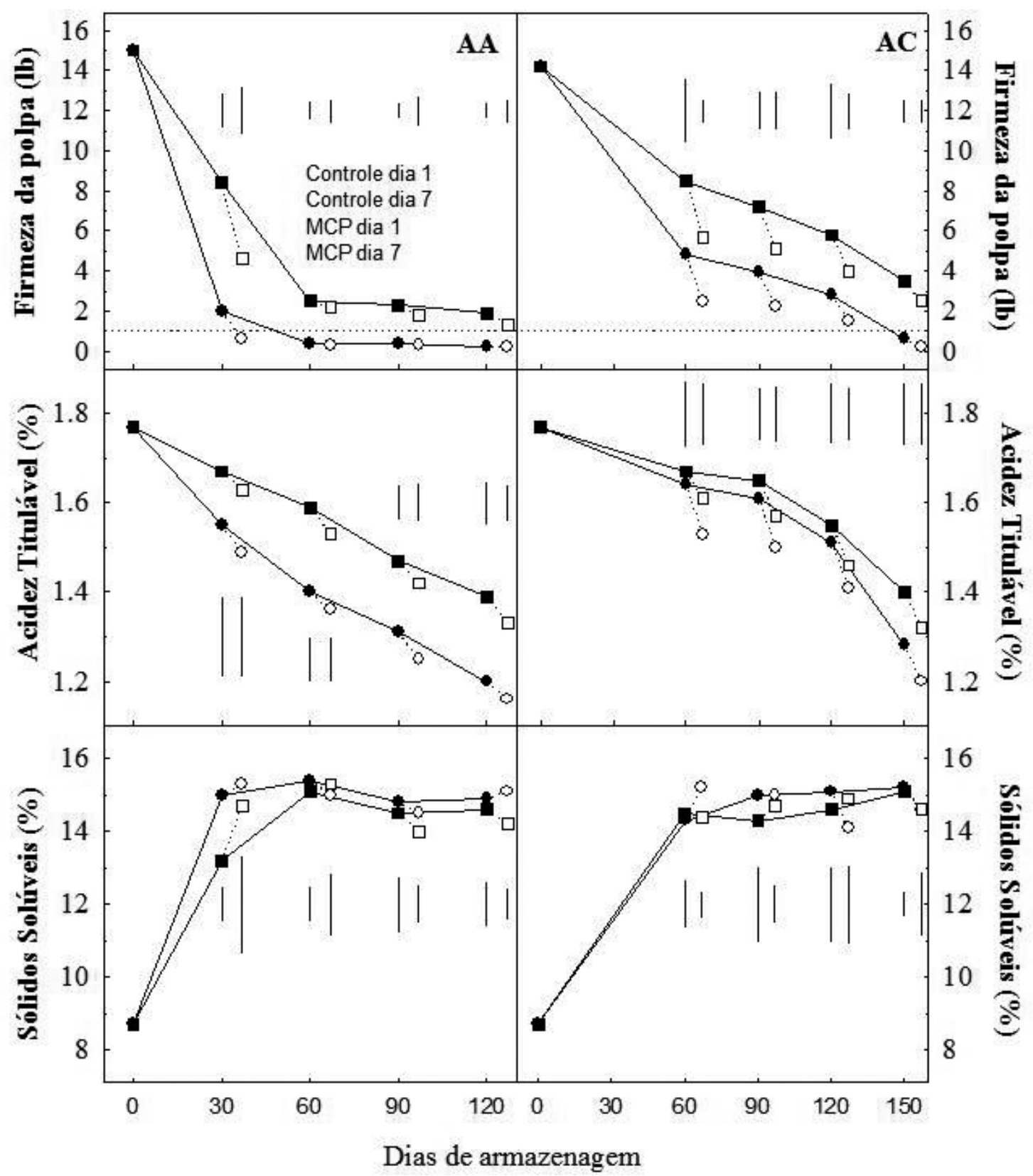

FIGURA 3- Firmeza da polpa (N), acidez titulável (\%) e sólidos solúveis (\%) em kiwi ‘Bruno', na colheita e após 30; 60; 90 e 120 dias de armazenamento sob atmosfera do ar (AA) e 60; 90; 120 e 150 dias de armazenamento sob atmosfera controlada (AC com baixo etileno), mais um e sete dias de prateleira a $23^{\circ} \mathrm{C}$. Os frutos foram tratados com 0,0 (controle) e $1,0 \mu \mathrm{L} . \mathrm{L}^{-1}$ de 1 -MCP. As barras verticais no interior de cada gráfico representam as diferenças mínimas significativas entre tratamentos, calculadas pelo teste de Fischer $(\mathrm{p}<0,05)$. Fraiburgo-SC (Dados médios de 2003 e 2004). 
TABELA 1 - Incidência de pericarpo translúcido (1 - ausência; 2 - presença) em kiwi ‘Bruno' tratado ou não com 1-MCP a 1,0 $\mu$ L.L-1 após armazenamento a $0 \mathrm{oC}$ sob atmosfera do ar e atmosfera controlada com baixo etileno, mais um e sete dias a 23oC. Fraiburgo-SC (Dados médios 2003 e 2004).

\begin{tabular}{|c|c|c|c|c|c|c|c|c|}
\hline \multirow{3}{*}{$\begin{array}{l}\text { Dias a } \\
0^{\circ} \mathrm{C}\end{array}$} & \multicolumn{4}{|c|}{ Atmosfera do ar (AA) } & \multicolumn{4}{|c|}{ Atmosfera controlada (AC) } \\
\hline & \multicolumn{2}{|c|}{1 dia a $23^{\circ} \mathrm{C}$} & \multicolumn{2}{|c|}{7 dias a $23^{\circ} \mathrm{C}$} & \multicolumn{2}{|c|}{1 dia a $23^{\circ} \mathrm{C}$} & \multicolumn{2}{|c|}{7 dias a $23^{\circ} \mathrm{C}$} \\
\hline & Controle & 1-МCP & Controle & 1-МCP & Controle & 1-MCP & Controle & 1-МCP \\
\hline 30 & $1,00 \mathrm{a}$ & $1,00 \mathrm{a}$ & $1,45 \mathrm{a}$ & $1,00 \mathrm{~b}$ & & & & \\
\hline 60 & $1,00 \mathrm{a}$ & $1,00 \mathrm{a}$ & $2,00 \mathrm{a}$ & $1,00 \mathrm{~b}$ & $1,00 \mathrm{a}$ & $1,00 \mathrm{a}$ & $1,00 \mathrm{a}$ & $1,00 \mathrm{a}$ \\
\hline 90 & $1,95 \mathrm{a}$ & $1,12 \mathrm{~b}$ & $2,00 \mathrm{a}$ & $1,30 \mathrm{~b}$ & $1,00 \mathrm{a}$ & $1,00 \mathrm{a}$ & $1,00 \mathrm{a}$ & $1,00 \mathrm{a}$ \\
\hline 120 & $1,96 \mathrm{a}$ & $1,20 \mathrm{~b}$ & $2,00 \mathrm{a}$ & $1,40 \mathrm{~b}$ & $1,00 \mathrm{a}$ & $1,00 \mathrm{a}$ & $1,00 \mathrm{a}$ & $1,00 \mathrm{a}$ \\
\hline 150 & & . & . & . & $1,64 \mathrm{a}$ & $1,08 \mathrm{~b}$ & $1,80 \mathrm{a}$ & $1,25 \mathrm{~b}$ \\
\hline
\end{tabular}

* Médias seguidas pela mesma letra na horizontal, entre tratamentos, para uma mesma data de avaliação e condição de armazenamento,não diferem significativamente, pelo teste de Fischer $(\mathrm{p}<0,05)$.

TABELA 2 - Incidência de pericarpo senescente (1 - ausência; 2 - presença) em kiwi 'Bruno' tratado ou não com 1-MCP a 1,0 $\mu$ L.L-1 após armazenamento a $0 \circ \mathrm{C}$ sob atmosfera do ar e atmosfera controlada com baixo etileno, mais um e sete dias a $23^{\circ} \mathrm{C}$. Fraiburgo-SC (Dados médios 2003 e 2004).

\begin{tabular}{|c|c|c|c|c|c|c|c|c|}
\hline \multirow{3}{*}{$\begin{array}{l}\text { Dias a } \\
0^{\circ} \mathrm{C}\end{array}$} & \multicolumn{4}{|c|}{ Atmosfera do ar (AA) } & \multicolumn{4}{|c|}{ Atmosfera controlada (AC) } \\
\hline & \multicolumn{2}{|c|}{1 dia a $23^{\circ} \mathrm{C}$} & \multicolumn{2}{|c|}{7 dias a $23^{\circ} \mathrm{C}$} & \multicolumn{2}{|c|}{1 dia a $23^{\circ} \mathrm{C}$} & \multicolumn{2}{|c|}{7 dias a $23^{\circ} \mathrm{C}$} \\
\hline & Controle & 1-MCP & Controle & 1-MCP & Controle & 1-МСР & Controle & 1-MCP \\
\hline 30 & $1,00 \mathrm{a}$ & $1,00 \mathrm{a}$ & $1,00 \mathrm{a}$ & $1,00 \mathrm{a}$ & & & & \\
\hline 60 & $1,00 \mathrm{a}$ & $1,00 \mathrm{a}$ & $1,20 \mathrm{a}$ & $1,00 \mathrm{a}$ & $1,00 \mathrm{a}$ & $1,00 \mathrm{a}$ & $1,00 \mathrm{a}$ & $1,00 \mathrm{a}$ \\
\hline 90 & $1,00 \mathrm{a}$ & $1,00 \mathrm{a}$ & $1,42 \mathrm{a}$ & $1,00 \mathrm{~b}$ & $1,00 \mathrm{a}$ & $1,00 \mathrm{a}$ & $1,00 \mathrm{a}$ & $1,00 \mathrm{a}$ \\
\hline 120 & $1,00 \mathrm{a}$ & $1,00 \mathrm{a}$ & $1,70 \mathrm{a}$ & $1,00 \mathrm{~b}$ & $1,00 \mathrm{a}$ & $1,00 \mathrm{a}$ & $1,00 \mathrm{a}$ & $1,00 \mathrm{a}$ \\
\hline 150 & . & & & . & $1,00 \mathrm{a}$ & $1,00 \mathrm{a}$ & $1,30 \mathrm{a}$ & $1,00 \mathrm{~b}$ \\
\hline
\end{tabular}

* Médias seguidas pela mesma letra na horizontal, entre tratamentos, para uma mesma data de avaliação e condição de armazenamento, não diferem significativamente, pelo teste de Fischer $(\mathrm{p}<0,05)$.

\section{CONCLUSÕES}

1-O tratamento com 1-MCP aumenta a conservação da firmeza da polpa e reduz o desenvolvimento de pericarpo translúcido e senescente, tanto para frutos armazenados sob atmosfera do ar (AA) quanto sob atmosfera controlada (AC com baixo etileno).

2-A redução da produção de etileno pelo 1-MCP, após remoção da câmara fria, é mais evidente nos frutos armazenados sob AC com baixo etileno que sob AA.
3-A redução da taxa respiratória e o aumento da conservação da acidez pelo 1-MCP, após remoção da câmara fria, são maiores nos frutos armazenados sob AA que sob AC.

4-O tratamento com 1-MCP aumenta o potencial de armazenamento em aproximadamente 30 dias sob AA e em 60 dias sob AC com baixo etileno.

5- Não há influência do tratamento com 1-MCP sobre o conteúdo de sólidos solúveis em ambas as condições de armazenamento. 


\section{REFERÊNCIAS}

ARGENTA, L.C.; KRAMMES, J.G.; MEGGUER, C.A.; AMARANTE, C.V.T. do; MATTHEIS, J. Ripening and quality of 'Laetitia' plums following harvest and cold storage as affected by inhibition of ethylene action. Pesquisa Agropecuária Brasileira, Brasília, v.38, n.10, p.1139-1148, 2003.

ARPAIA, M.L.; LABAVITCH, J.M.; GREVE, C.; KADER, A.A. Changes in the cell wall components of kiwifruit during storage in air or controlled atmospheres. Journal of the American Society for Horticultural Science, Alexandria, v.112, n. 3, p.417-481, 1987.

ARPAIA, M.L.; MITCHELL, F.G.; KADER, A.A. Postharvest physiology and causes of deterioration. In: HASEY, J.K.H.; JOHNSON, R.S.; GRANT, J.A.; REIL, W.O. Kiwifruit: growing and handling.. Davis: University of California, 1994. p.88-93.

ARPAIA, M.L.; MITCHELL, F.G.; KADER, A.A.; MAYER, G. Ethylene and temperature effects on softening and white core inclusions of kiwifruit stored in air or controlled atmospheres. Journal of the American Society for Horticultural Science, Alexandria, v.111, n.1, p.140-153, 1986.

ARPAIA, M.L.; MITCHELL, F.G.; KADER, A.A. Postharvest physiology and causes of deterioration. In: HASEY, J.K.H.; JOHNSON, R.S.; GRANT, J.A.; REIL, W.O. Kiwifruit: growing and handling.. Davis: University of California, 1994. p.88-93.

BRACKMANN, A.; ARRIEL, A.; OSTER, A.H. Armazenamento refrigerado de kiwi em atmosfera normal e controlada. Revista Brasileira de Agrociência, Pelotas, v.1, n.2, p.107-111, 1995.

BLANKENSHIP, S.M.; DOLE，J.M. 1-Methylcyclopropene: a review. Postharvest Biology and Technology, Amsterdam, v.28, n.28, p.1-25, 2003.

BONGHI, C.; PAGNI, S.; VIDRIH, R.; RAMINA, A.; TONUTTI, P. Cell wall hydrolases and amylase in kiwifruit softening. Postharvest Biology and Technology, Amsterdam, v.9, n.1, p.19-29, 1996.
BRECHT, J.K.; KADER, A.A. Regulation of ethylene production by ripening nectarine fruit as influenced by ethylene and low temperature. Journal of the American Society for Horticultural Science, Alexandria, v.109, n.6, p.869-872, 1984.

CRISOSTO, C.H.; MITCHAM, E.J.; KADER, A.A. Produce facts: kiwifruit recommendations for maintaining postharvest quality. Perishables Handling Quarterly, Davis, v.85, n.1, p19a-19b, 2000.

MANOLOPOULOU, H.; PAPADOPOULOU, P. A study of respiratory and physico-chemical changes of four kiwi fruit cultivars during cool storage. Food Chemistry, London, v.63, n.4, p.529-534, 1998. (corrigir no texto consta como 1997, correto 1998)

MAZARO, S.M.; BRACKMANN, A.; STORCK, L. Qualidade de kiwi armazenado em duas temperaturas sob atmosfera controlada e com eliminação do etileno. Ciência Rural, Santa Maria, v.30, n.6, p.947-952, 2000.

MITCHELL, F.G. Composition, maturity, and quality. In: HASEY, J.K.H.; JOHNSON, R.S.; GRANT, J.A.; REIL, W.O. Kiwifruit: growing and handling. Davis: University of California, 1994. p.94-107.

NEVES, L.C.; CORRENT, A.; MARINI, L.; LUCCHETA, L.; ZANUZZO, M.R.; GONÇALVES, E.D.; ZANATTA, J.; CANTILLANO, F.R.; ROMBALDI, C.V. Atmosfera modificada e 1-metilciclopropeno na conservação pós-colheita de kiwi.

Revista Brasileira de Fruticultura, Jaboticabal, v.25, n.3, p.390-393, 2003.

SCHUCK, E., Perspectivas da cultura do quivi no Planalto Catarinense. In: SEMINÁRIO NACIONAL SOBRE FRUTICULTURA DE CLIMA TEMPERADO, 8., 2008, São Joaquim. Resumos... Florianópolis: EPAGRI, 2008. p.100-105.

WACLAWOVSKY, A.J.; DONAZZOLO, J.; NEUWALD, D.A.; BRACKMANN, A. Qualidade póscolheita de kiwi (Actinidia deliciosa) cv. Bruno, tratados com 1-metilciclopropeno (1-MCP). In: CONGRESSO BRASILEIRO DE FISIOLOGIA VEGETAL, 8., 2001, Ilhéus. Anais... Ilhéus: SBFV, 2001. 1 CD-ROM. 